\title{
The need for polishing and occlusal adjustment of zirconia prostheses for wear on antagonist teeth
}

\author{
Keishu TACHIBANA ${ }^{1}$, Ikiru ATSUTA², Yoshihiro TSUKIYAMA ${ }^{3}$, Rika KUWATSURU ${ }^{1}$, Takehiro MORITA4 \\ Hiroya YOSHIMATSU ${ }^{5}$, Yasuyuki MATSUSHITA ${ }^{1}$, Ikue NARIMATSU ${ }^{1}$, Yasunori AYUKAWA ${ }^{1}$, Yoshinori SAWAE ${ }^{4}$ \\ and Kiyoshi KOYANO'
}

\author{
${ }^{1}$ Section of Implant and Rehabilitative Dentistry, Division of Oral Rehabilitation, Faculty of Dental Science, Kyushu University, 3-1-1 Maidashi, \\ Higashi-ku, Fukuoka 812-8582, Japan \\ ${ }^{2}$ Division of Advanced Dental Devices and Therapeutics, Faculty of Dental Science, Kyushu University, 3-1-1 Maidashi, Higashi-ku, Fukuoka 812- \\ 8582, Japan \\ ${ }^{3}$ Section of Dental Education, Division of Oral Biological Sciences, Faculty of Dental Science, Kyushu University, 3-1-1 Maidashi, Higashi-ku, \\ Fukuoka 812-8582, Japan \\ ${ }^{4}$ Machine Elements and Design Laboratory, Department of Mechanical Engineering, Kyushu University, 744 Motomachi, Nishi-ku, Fukuoka 819- \\ 0395, Japan \\ ${ }^{5}$ Faculty of Engineering, Kyushu University, 744 Motomachi, Nishi-ku, Fukuoka 819-0395, Japan \\ Corresponding author, Ikiru ATSUTA; E-mail: atyuta@dent.kyushu-u.ac.jp
}

The attrition of enamel when opposed by ceramics is of great concern. The purpose of this study was to evaluate enamel wear against high translucent zirconia (Zr), lithium disilicate (LD), gold ( $(\mathrm{Au})$, and enamel (E) with different surface and contact conditions. The materials were divided into two groups: polished and ground ( $n=8$ each). Two-body wear tests were performed against human enamel with vertical and horizontal, horizontal, and vertical repetitive movements as experiments 1 to 3 respectively. The surface roughness of all materials except $\mathrm{Zr}$ changed throughout the experiments. In experiment 1 , $\mathrm{Zr}$ and Au showed less antagonist wear when polished than when ground. In experiment 2, polished groups showed less antagonist wear than ground groups in all materials. In experiment 3, $\mathrm{Zr}$ and LD exerted greater antagonist wear than E, regardless of $R a$. These findings confirm the importance of polishing and occlusal adjustment of zirconia.

Keywords: Enamel wear, Zirconia, Polished surface, Ground surface, Occlusal contact

\section{INTRODUCTION}

For prosthodontic treatment, treatment that emphasizes functionality has been selected until recent years, when expectations for patient treatment have increased with the dramatic evolution of treatment technology and materials, and the improvement in strength and long-term durability of prosthetic devices. Esthetics, in addition to usable stability, have come to be considered important. For this reason, strong ceramics such as zirconia, which have a color close to that of teeth, are being selected more frequently than metal-colored crowns $^{1-6)}$. This choice seemed to promise long-term esthetics, but other problems, such as wear and fracture of the opposing teeth, still occur ${ }^{7-11)}$. In recent years, all-ceramic restorations have become increasingly popular ${ }^{12,13)}$. In particular, the clinical application of monolithic zirconia crowns has led to contact between ceramics with considerably high strength and the opposing enamel. Thus, wear on the opposing enamel has become a concern ${ }^{7}$.

Since 2010, enamel wear caused by opposing ceramics has been considered to be related to surface roughness more than hardness value ${ }^{14,15}$. It is reported that highly polished zirconia shows the least surface

Color figures can be viewed in the online issue, which is available at J-STAGE.

Received May 19, 2020: Accepted Aug 4, 2020

doi:10.4012/dmj.2020-190 JOI JST.JSTAGE/dmj/2020-190 roughness and antagonist wear among various dental ceramics and even natural enamel ${ }^{16-19)}$.

However, there are some inconsistencies in the studies about surface roughness and antagonist enamel wear ${ }^{11,13,18,20-22)}$. These conflicting results indicate that the effect of each material on the opposing enamel remains unclear.

Furthermore, differences in the wear rates of natural enamel and restorative materials can also change the occlusion ${ }^{23)}$. Therefore, periodic observation of the occlusal status and occlusal adjustment are required to maintain the stability of the occlusion ${ }^{24)}$. It is uncertain how thoroughly and effectively intraoral polishing can be performed, although intraoral polishing of the materials and natural teeth is needed in such cases. However, there are few studies comparing the antagonist wear of materials with rough surfaces (e.g., after occlusal adjustment through grinding) and smooth surfaces (e.g., after adequate polishing $)^{25}$. Additionally, the contact condition of each tooth against its antagonist is not constant in terms of its location and other factors. In other words, it can be "contact and slide", "slide backand-forth", or "repetitive contact". However, no studies have focused on the differences in the contact conditions. The hypothesis of this study was that the antagonist wear behavior of materials is not consistent, and depends on their surface roughness and contact conditions against 
their antagonists.

The purpose of this study was to evaluate human enamel wear when opposing high translucent zirconia, lithium disilicate, type 3 gold, and human enamel according to their surface roughness and contact conditions. Ground and polished surface conditions were prepared for each material, and differences in the degree of antagonist wear between the two conditions were investigated. In three experiments, vertical and horizontal movement, horizontal back-and-forth movement, and repetitive vertical movement were performed in distilled water. The null hypothesis of this study was "There is no statistically significant difference in antagonist enamel wear among these surface roughness and contact conditions."

\section{MATERIALS AND METHODS}

\section{Enamel antagonists}

One hundred and ninety-two similarly shaped, nonfunctional enamel cusps were dissected from extracted human maxillary and mandibular molars using a diamond point (Dia-Burs TR-14, Mani, Tochigi, Japan) under copious water irrigation. Each cusp was embedded in the middle of a drilled cap nut (FNT12,

(A)

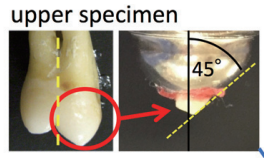

(B)

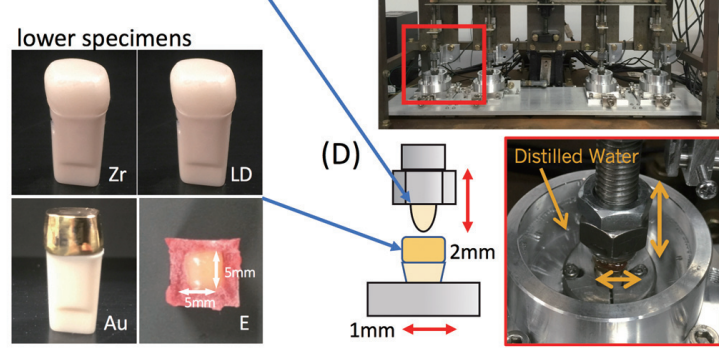

(E)

\begin{tabular}{|c|c|c|c|c|}
\hline \multirow[b]{2}{*}{ E) } & \multirow[b]{2}{*}{ Movement } & \multirow{2}{*}{$\begin{array}{l}\text { Number } \\
\text { of cycle }\end{array}$} & \multicolumn{2}{|c|}{ Valuation method } \\
\hline & & & $\begin{array}{c}\text { Surface } \\
\text { Roughness (Ra) }\end{array}$ & $\begin{array}{c}\text { Wear } \\
\left(10^{6} \mu \mathrm{m}^{3}\right)\end{array}$ \\
\hline Experiment 1 & $\begin{array}{l}\text { 稆 vertical \& horizontal } \\
\text { movement }\end{array}$ & 300,000 & Fig.3 & Fig.4 \\
\hline Experiment 2 & 蒠 horizontal movement & 450,000 & Fig.5 & Fig.6 \\
\hline Experiment 3 & 担 vertical movement & 900,000 & Fig.7 & Fig.8 \\
\hline
\end{tabular}

Fig. 1 (A) Upper specimens were prepared from nonfunctional cusps of extracted human molars. (B) Lower specimens were full-coverage crowns with a flat occlusal surface fabricated from each material, and human enamel that was prepared from the axial surface of human molars. (C) Photograph of the chewing simulation system. (D) Simplified diagram showing the movement of the chewing simulation system. (E) Experimental protocols for this study.
MISUMI, Tokyo, Japan) using self-curing acrylic resin (Pattern Resin, GC, Tokyo, Japan) [Fig. 1(A)]. Each maxillary specimen was fixed so that the angle formed between the external slope of the cusp and the occlusal surface of the mandibular specimen was $45^{\circ}$, and it was approximately perpendicular to the direction of the mandibular specimen's horizontal movement. The teeth used in this study were extracted within one year with the patients' consent, and stored in saline. Teeth with restorations, decalcification, caries, obvious abrasion, and fractures were excluded. This study was approved by the Research Ethics Committee of Kyushu University (approval number: A23-216-0).

\section{Specimen preparation}

As mandibular specimens, high translucent zirconia (Zr; inCoris TZI [3Y-TZP], Sirona, Bensheim, Germany), lithium disilicate (LD; e.max CAD, Ivoclar Vivadent, Schaan, Liechtenstein), type 3 gold (Au; K18, Ishifuku Metal Industry, Tokyo, Japan), and human enamel (E) were used.

Full-coverage crowns with flat occlusal surfaces were prepared using $\mathrm{Zr}, \mathrm{LD}$, and $\mathrm{Au}$ for molar abutment tooth models made of melamine resin. The occlusal thickness of each crown was approximately $1.5 \mathrm{~mm}$. This is the minimal thickness required for LD according to the manufacturer's instructions. Out of these three materials, LD required the greatest crown thickness; therefore, the thickness of the other two materials was also set to $1.5 \mathrm{~mm}$. $\mathrm{Zr}$ and $\mathrm{LD}$ crowns were fabricated using computer-aided design/computer-aided manufacturing by digital optical impression-taking (CEREC AC Omnicam, Sirona), milling (CEREC MC XL, Sirona), and firing (inFire HTC speed, Sirona/Programat CS, Ivoclar Vivadent). Au crowns were fabricated by one dental technician using the conventional lost-wax casting technique. Each crown was cemented to the models using self-adhesive resin cement (Clearfil SA Luting, Kuraray Noritake Dental, Tokyo, Japan) [Fig. 1(B)].

E specimens that were as flat as possible were prepared from the axial surfaces of human molars. The size of each E surface was approximately $5 \times 5 \mathrm{~mm}$, and the thickness extended from the enamel surface to the inner dentin surface. E specimens were fixed on top of resin blocks, the size of which was similar to the other tooth models, with the enamel surface facing upwards [Fig. 1(B)].

The mandibular specimens were divided into two groups: polished ( $n=8$ each) and ground ( $n=8$ each). The specimens in the polished group were well-polished under copious water irrigation by one dental technician using diamond-impregnated silicone polishing points (CERASHAIN 112C, M and F, GC) for $\mathrm{Zr}$ and $\mathrm{LD}$, and silicone polishing points (Bur No. 28, M2 and M3, SHOFU, Kyoto, Japan) for Au and E. Each polishing procedure was performed within $2 \mathrm{~min}$, which was the time taken for proper polishing in the preliminary experiment. The specimens in the ground group were ground using diamond points (Dia-Burs TR-14, Mani). Each polishing 
and grinding procedure was conducted with a light touch, copious water irrigation, and the appropriate rotating speed according to the manufacturers' instructions.

\section{Wear simulation}

In accordance with previous studies, a masticatory simulator was used in this study ${ }^{26,27)}$. Enamel antagonists were fixed on the upper holders with the angle described above, and the mandibular specimens were fixed on the lower holders with their upper surfaces as horizontal as possible.

As in Figs. 1(C)-(E), the specific parameters for these tests were: $49 \mathrm{~N}$ vertical force, $2 \mathrm{~Hz}$ frequency, $2 \mathrm{~mm}$ for vertical movement (i.e., enamel specimens impacted with mandibular specimens from $2 \mathrm{~mm}$ away), $1 \mathrm{~mm}$ for horizontal slide, and distilled water, based on the methods used in previous studies ${ }^{18,19,28,29)}$. Experiments 1 to 3 were performed as described below. The number of cycles was set according to the number at which the change on standing of the wear amount seemed to converge in a preliminary study.

Experiment 1: vertical and horizontal movement, 300,000 cycles.

Experiment 2: horizontal back-and-forth movement, 450,000 cycles.

Experiment 3: repetitive vertical movement, 900,000 cycles.

\section{Measurements}

Before and after testing, the surface roughness $(R a)$ of the mandibular specimens was measured using a laser scanning microscope with a width resolution

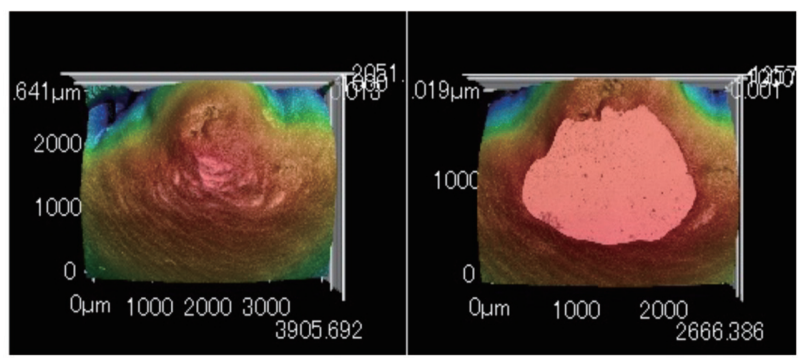

before the test

after the test

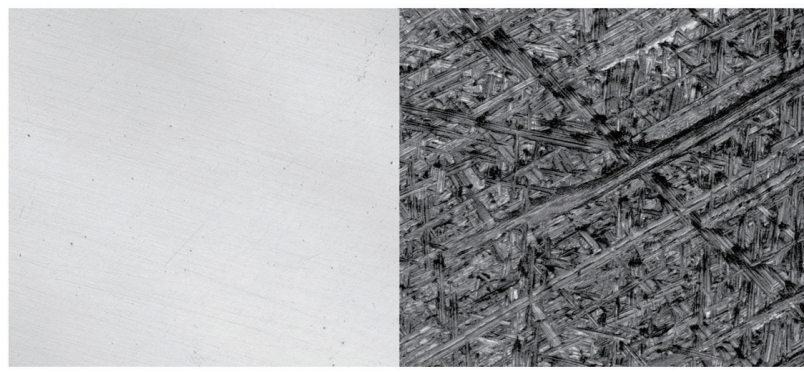

Fig. 2 The wear volume of upper specimens and the surface roughness of lower specimens before and after the experiments were calculated using a laser scanning microscope. of $0.5 \mathrm{~nm}$ and a height resolution of $1 \mathrm{~nm}$ (VK-X250, 260, Keyence, Osaka, Japan), based on ISO 4287:1997. Before testing, the specimen surfaces were considered to be homogeneous. The roughness was then measured at the center of each specimen, and five measurements per specimen were made for each $R a$ value (Fig. 2).

Before and after testing, the $3 \mathrm{D}$ profile of each antagonist was measured using the same laser scanning microscope. By comparing the volume of the cusp tip side before and after wear testing of the antagonists from the same cross-sectional area, the wear volume of each antagonist could be calculated (Fig. 2).

\section{Statistical analysis}

Statistical analysis was performed with a significance level of 5\% using SPSS Statistics 22 for Windows (IBM Japan, Tokyo, Japan). With respect to $R a$ value, the Kruskal-Wallis test and the Bonferroni multiple comparison test were used to determine the differences among the materials in each group before and after testing. The Wilcoxon signed rank test was used to determine the differences between before and after testing of each material. For antagonist wear, the Kruskal-Wallis test was followed by the Bonferroni multiple comparison test to determine the differences among the materials in each group. Mann-Whitney's $U$ test was used to analyze the differences between the two groups for each material.

\section{RESULTS}

\section{Experiment 1: vertical and horizontal movement}

1. Surface roughness

The surface roughness of each material in the polished group is presented in Fig. 3(A). Before wear testing, $\mathrm{Zr}$ and Au showed the lowest $R a$, followed in order by LD
(A) Polished Group
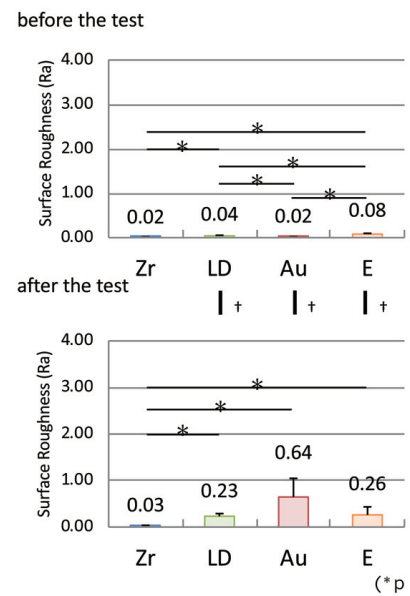

(B) Ground Group
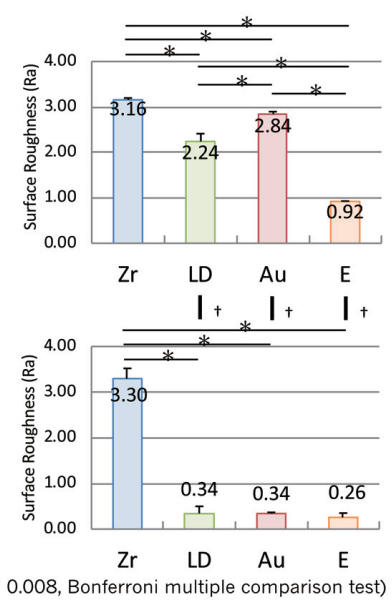

$\left({ }^{\dagger} p<0.05\right.$, Wilcoxon signed rank test)
Fig. 3 Surface roughness before and after the test in experiment 1.

(A) Polished group, (B) Ground group. 
and E. After the test, $\mathrm{Zr}$ showed a significantly lower $R a$ than $\mathrm{LD}, \mathrm{Au}$, and E. Comparison of the $R a$ between before and after the test revealed that the $R a$ of $\mathrm{LD}, \mathrm{Au}$, and $\mathrm{E}$ increased significantly.

The $R a$ of each material in the ground group is presented in Fig. 3(B). Before wear testing, $\mathrm{Zr}$ displayed the highest $R a$, followed in order by $\mathrm{Au}, \mathrm{LD}$, and E. After the test, $\mathrm{Zr}$ showed a significantly higher $R a$ than LD, $\mathrm{Au}$, and E. Comparison of the $R a$ between before and after the test revealed that the $R a$ of $\mathrm{LD}, \mathrm{Au}$, and $\mathrm{E}$ decreased significantly.

\section{Wear of antagonists}

Figure 4 shows the antagonist wear for each material. In the polished group, the antagonist wear of $\mathrm{Au}$ was significantly smaller than that of $\mathrm{Zr}, \mathrm{LD}$, and $\mathrm{E}$. The findings for the ground group may be summarized as follows: (1) the antagonist wear of Au was significantly smaller than $\mathrm{Zr}$, and was not significantly different when compared with LD and E; (2) the antagonist wear of $\mathrm{Zr}$ and $\mathrm{LD}$ was significantly larger than that of $\mathrm{E}$; and (3) there was no significant difference between the antagonist wear of $\mathrm{Zr}$ and LD.

For each material, the comparison between the antagonist wear of the two groups revealed a significant difference for $\mathrm{Zr}$ and $\mathrm{Au}$. Conversely, there was no difference for $\mathrm{LD}$ and $\mathrm{E}$.

\section{(A) Polished Group}

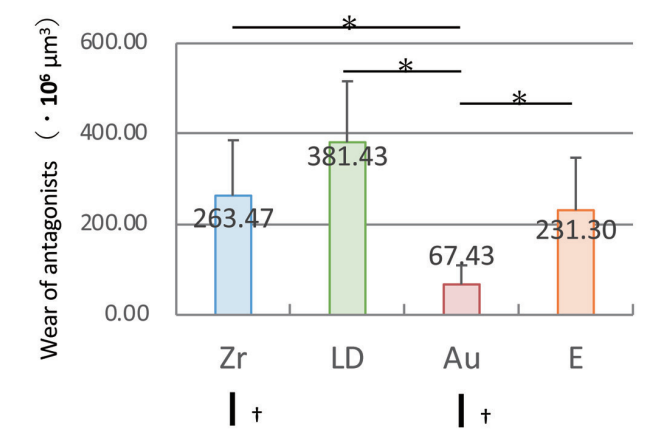

(B) Ground Group

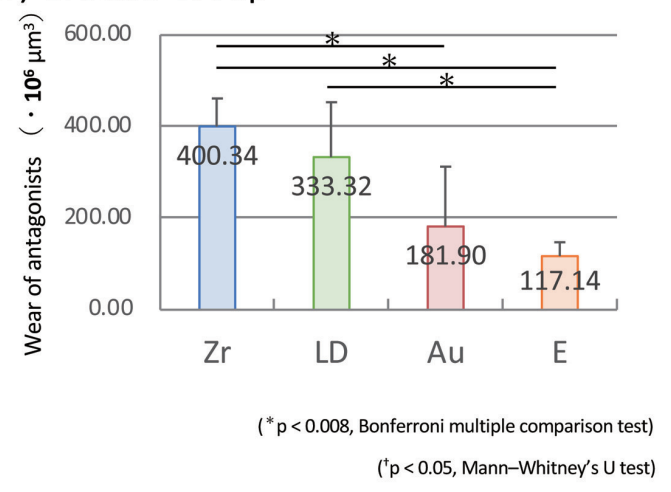

Fig. 4 Wear volume of the antagonist enamel in experiment 1.

(A) Polished group, (B) Ground group.
Experiment 2: horizontal back-and-forth movement 1. Surface roughness

The $R a$ of each material of the polished group is presented in Fig. 5(A). Before the test, $\mathrm{Zr}$ and $\mathrm{Au}$ recorded the lowest, $\mathrm{LD}$ the middle, and $\mathrm{E}$ the highest $R a$. After the

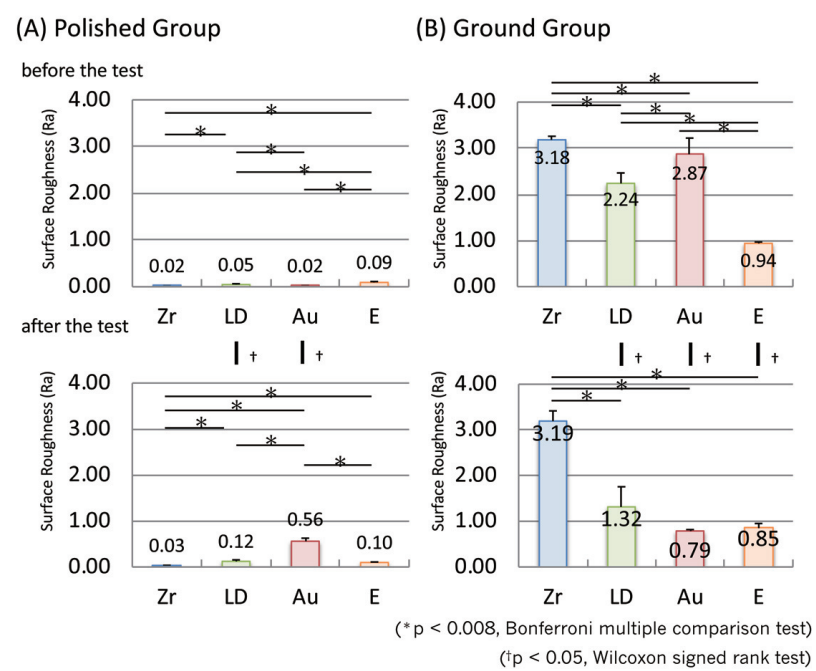

Fig. 5 Surface roughness before and after the test in experiment 2.

(A) Polished group, (B) Ground group.

(A) Polished Group

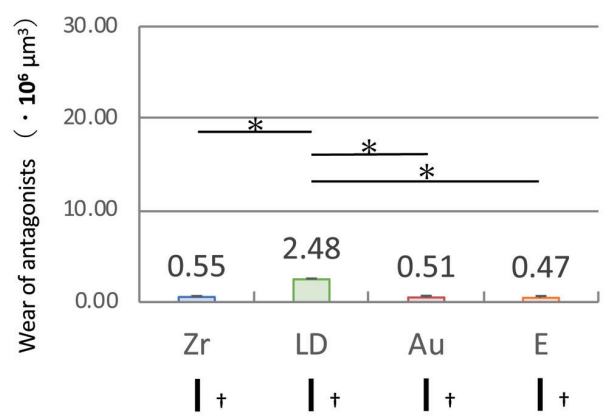

(B) Ground Group

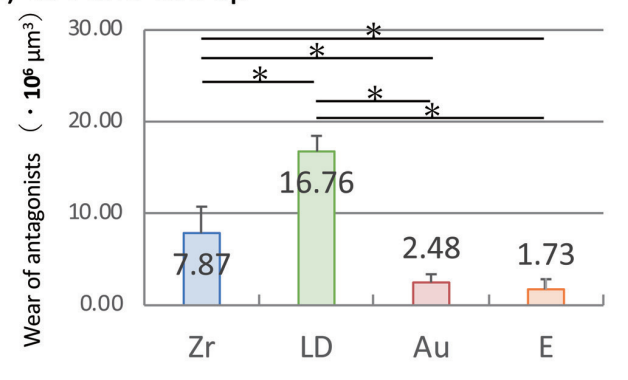

( ${ }^{*} \mathrm{p}<0.008$, Bonferroni multiple comparison test)

( ${ }^{+} \mathrm{p}<0.05$, Mann-Whitney's U test)

Fig. 6 Wear volume of the antagonist enamel in experiment 2.

(A) Polished group, (B) Ground group. 
test, $\mathrm{Zr}$ recorded the lowest, $\mathrm{LD}$ and $\mathrm{E}$ the middle, and Au the highest $R a$. Comparison of the $R a$ between before and after the test revealed that the $R a$ of $\mathrm{LD}$ and $\mathrm{Au}$ increased significantly.

(A) Polished Group

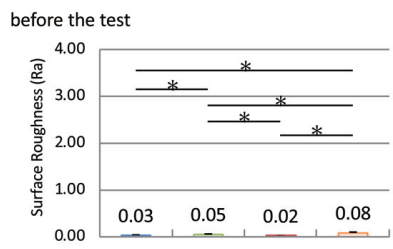

after the test $\mathrm{Zr} \quad \mathrm{LD} \quad \mathrm{Au} \quad \mathrm{E}$

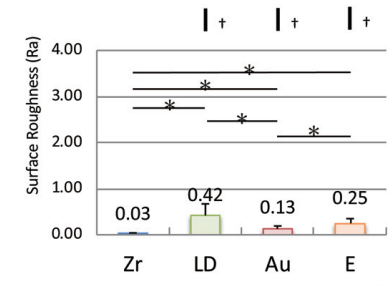

$\left({ }^{*} \mathrm{p}<0\right.$

(B) Ground Group
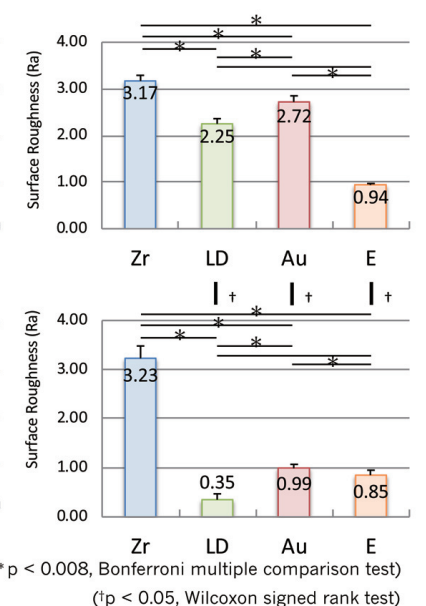

Fig. 7 Surface roughness before and after the test in experiment 3 .

(A) Polished group, (B) Ground group.

\section{(A) Polished Group}



(B) Ground Group

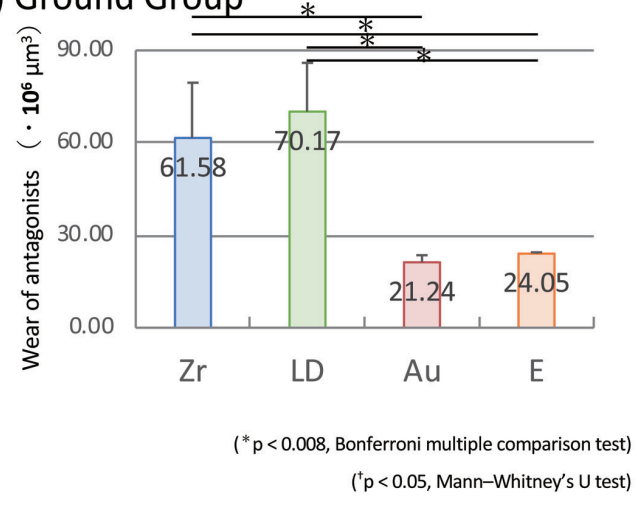

Fig. 8 Wear volume of the antagonist enamel in experiment 3.

(A) Polished group, (B) Ground group.
The $R a$ of each material of the ground group is presented in Fig. 5(B). Before wear testing, Zr displayed the highest $R a$, followed in order by $\mathrm{Au}, \mathrm{LD}$, and E. After the test, $\mathrm{Zr}$ displayed a significantly higher $R a$ than the other materials. Comparison of the $R a$ between before and after the test revealed that the $R a$ of $\mathrm{LD}, \mathrm{Au}$, and $\mathrm{E}$ decreased significantly.

\section{Wear of antagonists}

Figure 6 shows the antagonist wear of each material. In the polished group, the antagonist wear of LD was significantly larger than that of the other materials. In the ground group, the antagonist wear of LD was the largest, $\mathrm{Zr}$ the middle, $\mathrm{Au}$ and $\mathrm{E}$ the least.

The comparison between the antagonist wear of the two groups revealed that the ground group displayed greater antagonist wear than the polished group for all materials.

\section{Experiment 3: repetitive vertical movement}

1. Surface roughness

The $R a$ of each material in the polished group is presented in Fig. 7(A). Before the test, $\mathrm{Zr}$ and $\mathrm{Au}$ exhibited the lowest, $\mathrm{LD}$ the middle, and $\mathrm{E}$ the highest $R a$. After the test, $\mathrm{Zr}$ exhibited the lowest, Au the middle, and LD and $\mathrm{E}$ the highest $R a$. Comparison of the $R a$ between before and after the test revealed that the $R a$ of all materials other than Zr increased significantly.

The $R a$ of each material in the ground group is presented in Fig. 7(B). Before wear testing, Zr displayed the highest $R a$, followed in order by $\mathrm{Au}, \mathrm{LD}$, and E. After the test, Zr displayed the highest $R a$, followed in order by $\mathrm{Au}, \mathrm{E}$, and LD. Comparison of the $R a$ between before and after the test revealed that the $R a$ of all materials other than $\mathrm{Zr}$ decreased significantly.

\section{Wear of antagonists}

Figure 8 shows the antagonist wear of each material. In both groups, $\mathrm{Zr}$ and LD displayed significantly more antagonist wear than $\mathrm{Au}$ and $\mathrm{E}$. The comparison between the antagonist wear of the two groups revealed that the ground group showed greater wear than the polished group for $\mathrm{Au}$ and $\mathrm{E}$. However, for $\mathrm{Zr}$ and $\mathrm{LD}$, there was no difference between the two groups.

\section{DISCUSSION}

The results of this study suggest that $\mathrm{Zr}$ has high polishability. Figures 3(A), 5(A), and 7(A) show that before testing in the polished group, the $R a$ of $\mathrm{Zr}$ was not statistically different from that of $\mathrm{Au}$, and significantly lower than that of $\mathrm{LD}$ and E. This result is similar to that of a previous study, which reported that polished Zr has the lowest $R a$ when compared with other ceramics ${ }^{16)}$. It is presumed that differences in the microstructure of the materials could have affected the results. LD consists of lithium disilicate particles with a size of approximately $1.5 \mu \mathrm{m}$, whereas $\mathrm{Zr}$ consists of microparticles approximately $0.3-0.4 \mu \mathrm{m}$ in size ${ }^{30)}$. This is consistent with a previous report stating that the 
polishing efficacy of ceramics strongly depends on the material's microstructure ${ }^{31}$.

The $R a$ of $\mathrm{LD}$ and $\mathrm{Au}$ significantly increased after all tests. This suggests that the surfaces of restorations can be roughened or worn over time without any intervention such as occlusal adjustment, and that clinical repolishing of restorations may be needed. Conversely, there was no difference between the $R a$ of $\mathrm{Zr}$ before and after testing. It is considered that the prominent hardness value and fracture toughness of $\mathrm{Zr}$ contributed to this result, as described below. In Experiment 2, the $R a$ of polished $\mathrm{E}$ did not change throughout the test, indicating that the sliding movement alone barely changes the $R a$ of polished $\mathrm{E}$.

As shown in Figs. 3(B), 5(B), and 7(B), the $R a$ of all materials in the ground groups except $\mathrm{Zr}$ significantly decreased after the tests. The results for $\mathrm{Zr}$ in both groups suggest that $\mathrm{Zr}$ hardly changed its surface condition. Wear of ceramics (as well as enamel) is caused by a microfracture mechanism, but zirconia is less susceptible to microfracture than lithium disilicate because of its much higher fracture resistance ${ }^{22}$. This can rationally explain why $\mathrm{Zr}$ was the only material for which the $R a$ showed no significant difference before and after testing in both groups. This can be both an advantage for $\mathrm{Zr}$, in that its polished surface will remain smooth for a long period of time, and a disadvantage, in that a rough $\mathrm{Zr}$ surface will remain rough over time.

Figures 4, 6, and 8 show the antagonist wear volume. Lambrechts et al. reported that the vertical wear of enamel in the posterior region is $20-40 \mu \mathrm{m}$ in one year when there is no parafunction; therefore, changes in occlusion are expected over time and should be taken into consideration ${ }^{32}$. The antagonist wear of Au was less than that of $\mathrm{E}$ in all experiments, probably because of the ductility of the gold alloy ${ }^{12}$. It is thought that the wear or deformation of $\mathrm{Au}$ prevented excessive wear of the antagonists.

There was no difference between the two groups of $\mathrm{LD}$ in Experiment 1. According to $\mathrm{Ban}^{33)}$ and the manufacturer's technical data, the Vickers hardness and fracture toughness of $\mathrm{LD}$ are $580 \mathrm{Hv}$ and $2.25 \mathrm{MPa} \mathrm{m}^{1 / 2}$, respectively, which are much lower than those of Zr; 1,300 $\mathrm{Hv}$ and 6.4 $\mathrm{MPa} \mathrm{m}{ }^{1 / 2}$, respectively. For this reason, wear associated with microfracture might have occurred with $\mathrm{LD}$, thereby preventing excessive antagonist wear. The significant change in the $R a$ of $\mathrm{LD}$ indicates that wear of LD did occur, which supports this hypothesis. Surface roughness has a strong influence on the antagonist wear of ceramics, but it is also affected by the hardness or texture of the ceramic material ${ }^{34}$. In contrast, it was revealed that polishing of $\mathrm{Zr}$ significantly reduced its antagonist enamel wear. These findings suggest that the wear properties of materials like zirconia, which have considerably high hardness and fracture toughness, may be more strongly affected by surface roughness.

In Experiment 2, polishing of both $\mathrm{Zr}$ and $\mathrm{LD}$ was effective in reducing their antagonist wear. This is consistent with studies that reported that the surface roughness strongly affects the antagonist wear of ceramics $^{35,36)}$. The surface roughness is thought to have affected antagonist wear more than hardness or toughness in Experiment 2 because it included only a slide without any impact motion.

In Experiment 3, $\mathrm{Zr}$ and $\mathrm{LD}$ showed similar antagonist wear. Additionally, there was no difference between the polished and ground groups of both $\mathrm{Zr}$ and LD. This suggests that the surface roughness has no effect on the antagonists of ceramics in repetitive vertical movement without sliding.

In clinical studies, Stober et al. and Mundhe et al. reported that monolithic zirconia crowns on molars led to more antagonist enamel wear than natural enamel over 6 or 12 months $^{37,38)}$. The teeth involved were molars, which may have been in disclusion, causing the impact motion to occur without sliding. Therefore, this report supports the result of our study.

Our results must be interpreted with caution. Because the experiments were performed ex vivo, they could not perfectly simulate the intraoral conditions. Furthermore, the use of similar materials fabricated by different companies could cause variations in the results. In this study, a two-body wear test was performed, but a three-body wear test may be more appropriate to simulate the conditions of the oral cavity, which is affected by various uncontrollable factors, such as occlusal force, food properties, and the effects of saliva, tooth morphology, and masticatory pattern. Although the results of our study suggest the need to repolish restorations or teeth, the polishability of materials within the oral cavity remains unknown. Further studies that simulate intraoral conditions more accurately, including controlling the factors listed above, are required. Future clinical studies should be conducted with extended observation periods and larger sample sizes.

\section{CONCLUSION}

Polished $\mathrm{Zr}$ is preferable in terms of opposing enamel wear, and, because $\mathrm{Zr}$ is a much harder material, it can maintain a smoother state once polished compared with the other materials. However, rough Zr can also maintain its surface roughness, and can cause major wear of the antagonist teeth, depending on the occlusion conditions. In contrast, although both Au and LA have less effect on the antagonist teeth, Au is inferior esthetically, and LA is inferior in terms of strength. These results confirm the importance of polishing and occlusal adjustment for zirconia material.

\section{ACKNOWLEDGMENTS}

This study was supported by a Grant-in-Aid for scientific research from the Japan Society for the Promotion of Science (No. 15K11163) to Y. T. We also thank Helen Jeays, BDSc AE, from Edanz Group (https://en-authorservices.edanzgroup.com/ac) for editing a draft of this manuscript. 


\section{CONFLICT OF INTEREST}

The authors declare that they have no conflict of interest.

\section{REFERENCES}

1) Alghazzawi TF, Lemons J, Liu PR, Essig ME, Janowski GM. Evaluation of the optical properties of CAD-CAM generated yttria-stabilized zirconia and glass-ceramic laminate veneers. J Prosthet Dent 2012; 107: 300-308.

2) Baldissara P, Llukacej A, Ciocca L, Valandro FL, Scotti R. Translucency of zirconia copings made with different CAD/ CAM systems. J Prosthet Dent 2010; 104: 6-12.

3) Pjetursson BE, Sailer I, Zwahlen M, Hämmerle CH. A systematic review of the survival and complication rates of all-ceramic and metal-ceramic reconstructions after an observation period of at least 3 years. Part I: single crowns. Clin Oral Implants Res 2007; 18: Suppl 3, 73-85.

4) Takeichi T, Katsoulis J, Blatz MB. Clinical outcome of single porcelain-fused-to-zirconium dioxide crowns: a systematic review. J Prosthet Dent 2013; 110: 455-461.

5) Sailer I, Makarov NA, Thoma DS, Zwahlen M, Pjetursson BE. All-ceramic or metal-ceramic tooth-supported fixed dental prostheses (FDPs)? A systematic review of the survival and complication rates. Part I: single crowns (SCs). Dent Mater 2015; 31: 603-623.

6) Heintze SD, Cavalleri A, Zellwegera G, Buchler A, Zappinia G. Fracture frequency of all-ceramic crowns during dynamic loading in a chewing simulator using different loading and luting protocols. Dent Mater 2008; 24: 1352-1361.

7) Jagger DC, Harrison A. An in vitro investigation into the wear effects of selected restorative materials on enamel. J Oral Rehabil 1995; 22: 275-281.

8) Elmaria A, Goldstein G, Vijayaraghavan T, Legeros RZ, Hittelman EL. An evaluation of wear when enamel is opposed by various ceramic materials and gold. J Prosthet Dent 2006; 96: 345-353.

9) Wiley MG. Effects of porcelain on occluding surfaces of restored teeth. J Prosthet Dent 1989; 61: 133-137.

10) Hudson JD, Goldstein GR, Georgescu M. Enamel wear caused by three different restorative materials. J Prosthet Dent 1995; 74: 647-654.

11) Chong BJ, Thangavel AK, Rolton SB, Guazzato M, Klineberg IJ. Clinical and laboratory surface finishing procedures for zirconia on opposing human enamel wear: A laboratory study. J Mech Behav Biomed Mater 2015; 50: 93-103.

12) Kadokawa A, Suzuki S, Tanaka T. Wear evaluation of porcelain opposing gold, composite resin, and enamel. J Prosthet Dent 2006; 96: 258-265.

13) Lawson NC, Janyavula S, Syklawer S, McLaren EA, Burgess JO. Wear of enamel opposing zirconia and lithium disilicate after adjustment, polishing and glazing. J Dent 2014; 42: 1586-1591.

14) Heintze SD, Cavalleri A, Forjanic M, Zellweger G, Rousson V. Wear of ceramic and antagonist--a systematic evaluation of influencing factors in vitro. Dent Mater 2008; 24: 433-449.

15) Oh WS, Delong R, Anusavice KJ. Factors affecting enamel and ceramic wear: a literature review. J Prosthet Dent 2002; 87: 451-459.

16) Janyavula S, Lawson N, Cakir D, Beck P, Ramp LC, Burgess JO. The wear of polished and glazed zirconia against enamel. J Prosthet Dent 2013; 109: 22-29.

17) Miyazaki T, Nakamura T, Matsumura H, Ban S, Kobayashi T. Current status of zirconia restoration. J Prosthodont Res 2013; 57: 236-261.

18) Preis V, Behr M, Kolbeck C, Hahnel S, Handel G, Rosentritt $\mathrm{M}$. Wear performance of substructure ceramics and veneering porcelains. Dent Mater 2011; 27: 796-804.

19) Stawarczyk B, Ozcan M, Schmutz F, Trottmann A, Roos M, Hammerle CH. Two-body wear of monolithic, veneered and glazed zirconia and their corresponding enamel antagonists. Acta Odontol Scand 2013; 71: 102-112.

20) Luangruangrong P, Cook NB, Sabrah AH, Hara AT, Bottino MC. Influence of full-contour zirconia surface roughness on wear of glass-ceramics. J Prosthodont 2014; 23: 198-205.

21) Burgess JO, Janyavula S, Lawson NC, Lucas TJ, Cakir D. Enamel wear opposing polished and aged zirconia. Oper Dent 2014; 39: 189-194.

22) Sripetchdanond J, Leevailoj C. Wear of human enamel opposing monolithic zirconia, glass ceramic, and composite resin: An in vitro study. J Prosthet Dent 2014; 112: 11411150.

23) Yip KH, Smales RJ, Kaidonis JA. Differential wear of teeth and restorative materials: clinical implications. Int $\mathrm{J}$ Prosthodont 2004; 17: 350-356.

24) Rosentritt M, Preis V, Behr M, Hahnel S, Handel G, Kolbeck C. Two-body wear of dental porcelain and substructure oxide ceramics. Clin Oral Investig 2012; 16: 935-943.

25) Mitov G, Heintze SD, Walz S, Woll K, Muecklich F, Pospiech P. Wear behavior of dental Y-TZP ceramic against natural enamel after different finishing procedures. Dent Mater 2012; 28: 909-918.

26) Sawae Y, Sakamoto A, Ikegami T, Matsushita Y, Sakai N, Murakami T, et al. Mechanical test of temporary cementation for dental implant using a mastication simulator. Jpn J Clin Biomech 2005; 26: 153-158 (In Japanese).

27) Mieda M, Atsuta I, Matsushita Y, Morita T, Ayukawa Y, Tsukiyama Y. et al. The effective design of zirconia coping on titanium base in dental implant superstructure. Dent Mater J 2018; 37: 237-243.

28) Gibbs CH, Mahan PE, Lundeen HC, Brehnan K, Walsh EK, Holbrook WB. Occlusal forces during chewing and swallowing as measured by sound transmission. J Prosthet Dent 1981; 46: 443-449.

29) Rosentritt M, Behr M, Gebhard R, Handel G. Influence of stress simulation parameters on the fracture strength of allceramic fixed-partial dentures. Dent Mater 2006; 22: 176182.

30) Ban S. Current status of CAD/CAM biomaterials. J Jpn Acad CAD/CAM Dent 2013; 3: 2-10 (In Japanese).

31) Ban S, Sakakibara T, Yoshihara K, Takeuchi M, Kawai T, Murakami H, et al. Surface properties of dental zirconia after clinical grinding and polishing. Key Eng Mater 2013: 501506.

32) Lambrechts P, Braem M, Vuylsteke-Wauters M, Vanherle G. Quantitative in vivo wear of human enamel. J Dent Res 1989; 68: 1752-1754.

33) Ban S. Chemical durability of high translucent dental zirconia. Dent Mater J 2020; 39: 12-23

34) Krejci I, Lutz F, Reimer M, Heinzmann JL. Wear of ceramic inlays, their enamel antagonists, and luting cements. $\mathrm{J}$ Prosthet Dent 1993; 69: 425-430.

35) Magne P, Oh WS, Pintado MR, DeLong R. Wear of enamel and veneering ceramics after laboratory and chairside finishing procedures. J Prosthet Dent 1999; 82: 669-679.

36) Seghi RR, Rosenstiel SF, Bauer P. Abrasion of human enamel by different dental ceramics in vitro. J Dent Res 1991; 70: 221-225.

37) Stober T, Bermejo JL, Rammelsberg P, Schmitter M. Enamel wear caused by monolithic zirconia crowns after 6 months of clinical use. J Oral Rehabil 2014; 41: 314-322.

38) Mundhe K, Jain V, Pruthi G, Shah N. Clinical study to evaluate the wear of natural enamel antagonist to zirconia and metal ceramic crowns. J Prosthet Dent 2015; 114: 358363. 